\title{
Análise de Crescimento de Biótipos de Amendoim-Bravo (Euphorbia heterophylla) Resistente e Suscetível aos Herbicidas Inibidores DA ALS $\mathbf{S}^{1}$
}

\author{
Growth Analysis of Wild Poinsettia (Euphorbia heterophylla) Biotypes Resistant and \\ Susceptible to ALS Inhibitor Herbicides
}

\author{
BRIGHENTI, A.M. ${ }^{2}$, GAZZIERO, D.L.P. ${ }^{2}$, VOLL, E. ${ }^{2}$, ADEGAS, F.S. ${ }^{3}$ e VAL, W.M.C. ${ }^{2}$
}

\begin{abstract}
RESUMO - A aplicação contínua de herbicidas do grupo químico das imidazolinonas, nas mesmas áreas de produção de soja, durante anos seguidos, no município de Cafelândia, PR, favoreceu a seleção de um biótipo resistente de amendoim-bravo (Euphorbia heterophylla) aos herbicidas inibidores da acetolactato sintase (ALS). Um estudo comparativo das características do crescimento do biótipo resistente e do suscetível foi realizado em casa de vegetação da Embrapa Soja, Londrina-PR, a fim de identificar diferenças no crescimento e no desenvolvimento das plantas e de seus órgãos. A produção de matéria seca total, a área foliar, a matéria seca dos caule, das raízes e das folhas, bem como a altura por planta, foram avaliadas em 13 vezes a intervalos regulares, iniciando aos 14 dias após a semeadura. A partir desses parâmetros, foram calculadas a taxa de crescimento relativo, a taxa assimilatória líquida, a razão de área foliar, a razão de peso foliar e a área foliar específica, que decrescem com a ontogenia das plantas de amendoim-bravo, sendo similares para ambos os biótipos. A matéria seca total acumulada pelas plantas e seus órgãos, a área foliar e a altura apresentaram comportamentos semelhantes para os biótipos resistente e suscetível. O ciclo vegetativo dos dois biótipos estudados não mostrou diferença significativa quanto ao crescimento e ao desenvolvimento.
\end{abstract}

Palavras-chave: resistência a herbicidas, área foliar, taxa de crescimento.

\begin{abstract}
Repetitive spraying of imidazolinone herbicides year after year to control weeds in the soybean grown areas of Cafelândia, Paraná, Brazil, has favored the selection of an ALS (acetolactate synthase) inhibitor herbicide resistant biotype of wild poinsettia (Euphorbia heterophylla). A comparative study of growth and development of wild poinsettia resistant and susceptible to ALS inhibitor herbicides was carried out in the greenhouse of the experimental station of Soybean Embrapa in Londrina, Paraná, Brazil. Total dry biomass yield, leaf area, shoot dry weight, leaf dry weight, root dry weight and height per plant were measured 13 times at 2 week intervals, starting 14 days after sowing. Relative growth rate, net assimilation rate, leaf area ratio, leaf weight ratio and specific leaf area decreased with plant ontogeny and behaved similarly in both biotypes. The total dry matter of the plants and their organs as well as the leaf area and plant height exhibited similar ranges of variability in both biotypes. There were no significant differences between biotypes both for growth and development characteristics.
\end{abstract}

Key words: herbicide resistance, leaf area, growth rate.

Recebido para publicação em 3/1/2000 e na forma revisada em 13/4/2000.

2 Eng.-Agrônomo, Pesquisador-Embrapa Soja, Caixa Postal 231, 86001-970 Londrina-PR.; ${ }^{3}$ Eng.-Agrônomo da Emater, Caixa Postal 763, 86001-970 Londrina-PR.

Planta Daninha, Viçosa-MG, v.19, n.1, p.51-59, 2001 


\section{INTRODUÇÃO}

A planta daninha amendoim-bravo (Euphorbia heterophylla) é uma espécie bastante freqüente em todo o Brasil, e produtores de soja encontram dificuldades no seu controle. Possui extraordinária capacidade de reprodução e as plantas crescem com muita rapidez, razão pela qual tendem a sombrear plantas de culturas anuais de desenvolvimento mais lento, competindo intensamente na absorção de nutrientes do solo (Kissmann \& Groth, 1992).

Nos últimos dez anos, herbicidas do grupo químico das imidazolinonas, sulfoniluréias e triazolopirimidinas, que inibem a ação da acetolactato sintase (ALS), têm sido utilizados no controle dessa planta daninha (Rodrigues \& Almeida, 1998). Entretanto, a presença de populações de amendoim-bravo resistentes aos herbicidas que apresentam esse mecanismo de ação foi confirmada em algumas regiões produtoras de soja no Brasil e relatadas por Vidal \& Fleck (1997), Vidal et al. (1997a), Vidal et al. (1997b) e Gazziero et al. (1998).

O desenvolvimento da resistência de plantas daninhas aos herbicidas pode ser evitado pelo conhecimento dos fatores envolvidos no processo. Estudos referentes ao entendimento dos padrões de crescimento e desenvolvimento das plantas daninhas são muito importantes para detectar diferenças entre biótipos de uma mesma espécie quanto à sua adaptabilidade (Holt \& Radosevich, 1983). Nesse contexto, a análise de crescimento de plantas é uma ferramenta importante para aqueles pesquisadores que estão interessados em conhecer diferenças funcionais e estruturais entre cultivares de uma espécie e muito útil no estudo do comportamento vegetal sob diferentes condições ambientais e de cultivo, incluindo-se nesse caso a ocorrência das plantas daninhas (Benincasa et al., 1980; Benincasa, 1988).

Desse modo, modelos matemáticos que expressam o crescimento e suas características derivadas (taxa de crescimento relativo, taxa assimilatória líquida) fornecem subsídios para melhor compreensão dos diferentes processos fisiológicos envolvidos na morfogênese das plantas (Calbo et al., 1989).

O objetivo deste trabalho foi comparar as características do crescimento do amendoimbravo resistente e suscetível aos herbicidas inibidores da ALS, a fim de identificar diferenças no crescimento e no desenvolvimento das plantas e de seus órgãos.

\section{MATERIAL E MÉTODOS}

Sementes de amendoim-bravo foram coletadas na localidade Central dos Jesuítas, município de Cafelândia-PR, onde a soja vinha sendo cultivada durante oito anos com aplicações sucessivas de imazaquin. Na safra 95/ 96, foi observado que a aplicação do herbicida imazethapyr estava apresentando falhas no controle dessa planta daninha. Paralelamente, também foram colhidas sementes em área onde não havia sido utilizado nenhum tipo de herbicida, considerando essas plantas como suscetíveis (biótipo S) aos herbicidas inibidores da ALS. Ambos os biótipos foram avaliados por Gazziero et al. (1998), e o biótipo suspeito foi confirmado como resistente (biótipo R), apresentando diferentes níveis de resistência cruzada aos herbicidas cloransulan, imazethapyr e imazaquin.

O experimento foi instalado em casa de vegetação da Embrapa Soja, município de Londrina-PR, situado a $23^{\circ} 23^{\prime}$ de latitude sul e $51^{\circ} 11^{\prime}$ de longitude oeste, durante o período de 21 de outubro de 1998 a 21 de abril de 1999. Sementes do biótipo suscetível e do resistente foram semeadas separadamente em vasos plásticos com 8,0 L de capacidade. O material utilizado para enchimento dos vasos foi composto da mistura de três partes de solo para uma de húmus. A análise química do substrato utilizado encontra-se na Tabela 1.

Após a emergência das plantas, foi realizado o desbaste, deixando-se cinco plantas por vaso. Os vasos foram irrigados, mantendo-se o nível de água próximo à capacidade de campo.

O experimento foi conduzido em delineamento inteiramente casualizado, com três repetições. Foram realizadas 13 coletas a intervalos de 14 dias, e todas as determinações foram feitas em cinco plantas contidas em cada vaso. Na época da coleta, as plantas foram cortadas rente ao solo e separadas em caules, folhas e raizes. Estas foram retiradas e lavadas em água corrente, para remoção de partículas de solo. As plantas foram colocadas em sacos plásticos, cobertas com camadas de gelo, acondicionadas em caixa de isopor e, em seguida, levadas ao laboratório. 
Tabela 1 - Análise química do substrato utilizado para enchimento dos vasos. Embrapa Soja, Londrina, PR, 1999 ${ }^{1}$

\begin{tabular}{|c|c|c|c|c|c|c|c|c|}
\hline \multirow{2}{*}{$\begin{array}{c}\mathrm{P} \\
\mathrm{mg} \mathrm{dm}^{-3}\end{array}$} & \multirow{2}{*}{$\begin{array}{c}\mathrm{pH} \\
\mathrm{CaCl}_{2} \\
\end{array}$} & $\mathrm{Al}^{+3}$ & $\mathrm{~K}$ & $\mathrm{Ca}$ & $\mathrm{Mg}$ & $\mathrm{H}^{+}+\mathrm{Al}^{+3}$ & SB & CTC \\
\hline & & \multicolumn{7}{|c|}{ - } \\
\hline 73,70 & 5,70 & 0,0 & 0,61 & 10,45 & 2,59 & 3,29 & 13,65 & 16,94 \\
\hline
\end{tabular}

'Resultados fornecidos pelo laboratório de análises de solos da Embrapa Soja.

A área foliar (Af) foi determinada por meio de medidor fotoelétrico, marca LI-COR, modelo 3100, Nebraska, USA. Para obtenção da matéria seca, o material foi colocado em sacos de papel, contendo separadamente folhas, caules e raízes, deixado em estufa de ventilação forçada a $70^{\circ} \mathrm{C}$ por $48 \mathrm{~h}$ e pesado. Além disso, foi avaliada a altura das plantas de amendoim-bravo.

Os dados primários da matéria seca total (Wt), dos órgãos, da área foliar e da altura de plantas foram submetidos à análise de variância e regressão, procurando determinar o polinômio que melhor se ajustasse aos dados primários, em função do tempo (Calbo et al., 1989). Os valores estimados, para as características de crescimento mencionadas, foram comparados, durante todo o ciclo do amendoim-bravo, utilizando o intervalo de confiança de $95 \%$.

Os valores instantâneos de taxa de produção de matéria seca total $(\mathrm{Ct})$ foram determinados pela derivada da equação ajustada ao peso da matéria seca total (Wt) em relação ao tempo (t), conforme Radford (1967) e Richards (1969).

A taxa de crescimento relativo ( $\mathrm{Rw})$ e a taxa assimilatória líquida (Ea) foram calculadas por meio das fórmulas $\mathrm{Rw}=\mathrm{Ct} / \mathrm{Wt}$ e $\mathrm{Ea}=\mathrm{Ct} / \mathrm{Af}$, respectivamente.

A razão de área foliar $(\mathrm{Fa})$, a área foliar específica (Sa) e a razão de peso foliar (Fw) foram determinadas a partir de valores instantâneos de Af, Wf e Wt, empregados nas equações $\mathrm{Fa}=\mathrm{Af} / \mathrm{Wt}, \mathrm{Sa}=\mathrm{Af} / \mathrm{Wf}$ e $\mathrm{Fw}=\mathrm{Wf} / \mathrm{Wt}$, conforme Radford (1967) e Richards (1969).

\section{RESULTADOS E DISCUSSÃO}

O acúmulo de matéria seca total (Wt) apresentou comportamento semelhante para ambos os biótipos estudados (Figura 1 e Tabela 2). Os valores máximos de $\mathrm{Wt}$ obtidos foram de 41 e 39 g planta $^{-1}$, aos 134 e 133 dias após semeadura (DAS) para o biótipo considerado resistente e o suscetivel, respectivamente. A produção de matéria seca de biótipos de Senecio vulgaris e Amaranthus retroflexus, resistentes e suscetiveis ao herbicida atrazine, foi comparada por Conard \& Radosevich (1979), os quais verificaram que essa característica foi maior nos biótipos considerados suscetíveis. Entretanto, a partição de assimilados destinada às partes reprodutivas, aos caules e às raízes foi semelhante entre os biótipos de cada espécie estudada.

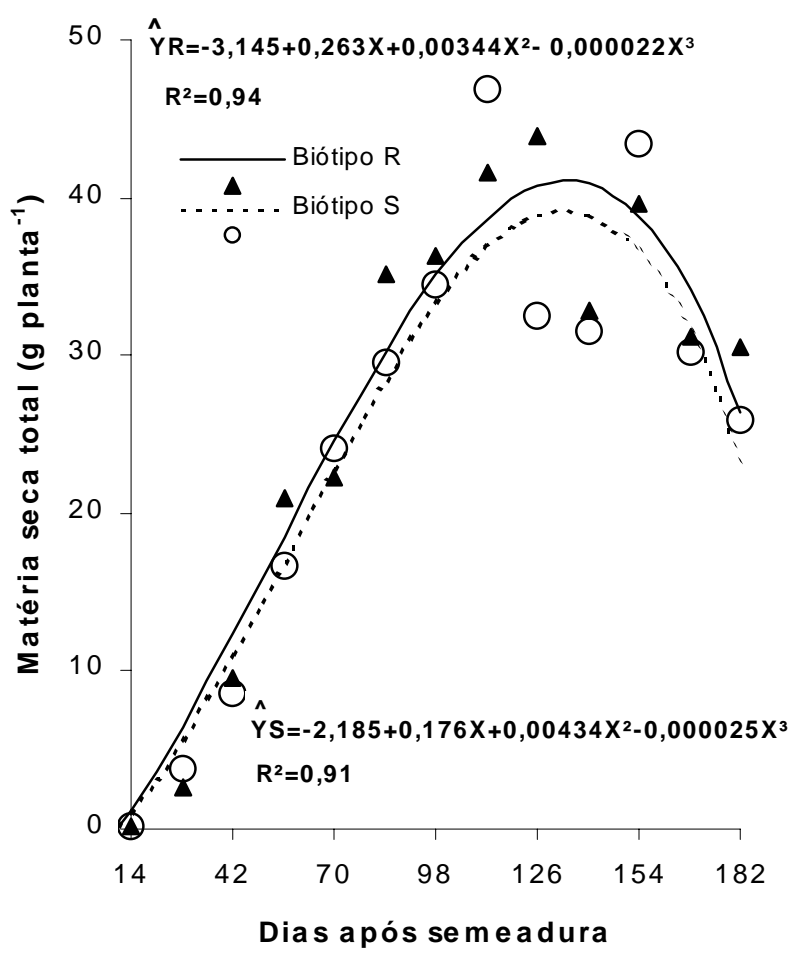

Figura 1 - Matéria seca total de plantas de amendoim-bravo, em função do tempo.

Planta Daninha, Viçosa-MG, v.19, n.1, p.51-59, 2001 


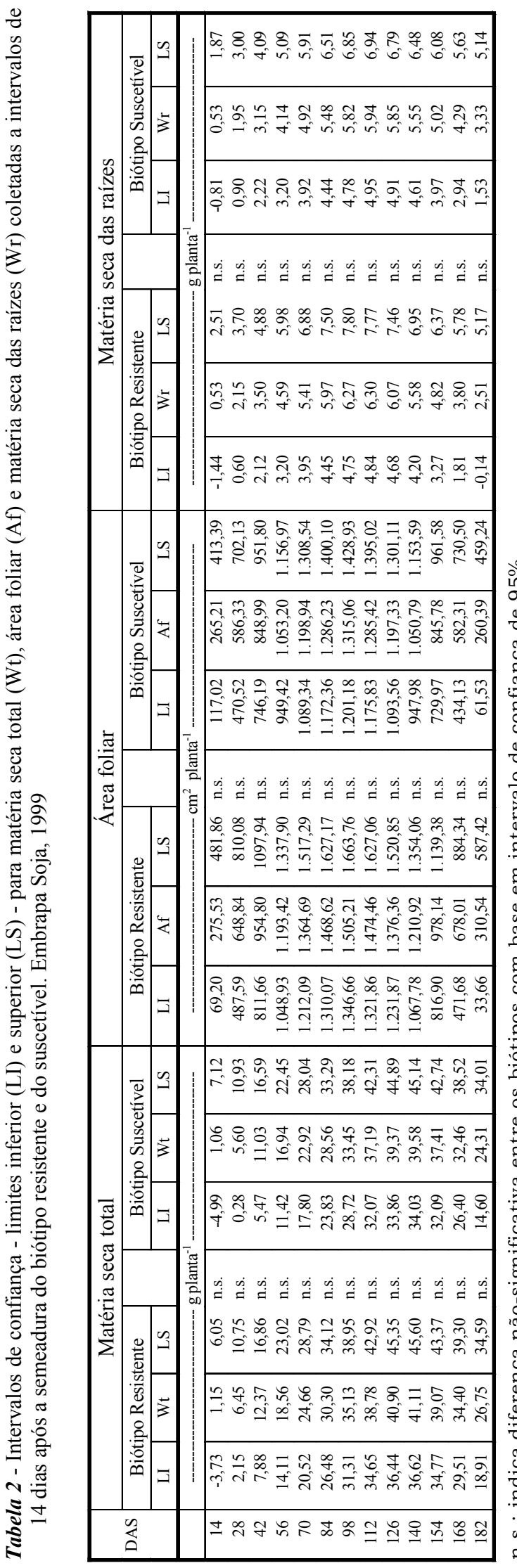

A taxa de crescimento relativo (Rw) está representada na Figura 2. Observa-se que, tanto para o biótipo R quanto para o S, os valores iniciais de $\mathrm{Rw}$ são relativamente altos e decrescem rapidamente por volta dos 42 DAS. Esse declínio continuou lentamente até próximo aos 130 DAS. O comportamento foi bastante similar entre os biótipos estudados, havendo sobreposição das curvas durante a maior parte do período avaliado. Biótipos de Lactuca serriola resistentes e suscetiveis aos herbicidas do grupo químico das sulfoniluréias foram comparados quanto ao crescimento, em condições de casa de vegetação. Foi constatado que a taxa de crescimento relativo foi maior no biótipo suscetível, sendo o acúmulo de matéria seca $52 \%$ mais rápido nesse biótipo do que no resistente (Alocer-Ruthling et al., 1992). Rw assemelha-se ao comportamento da curva de razão de área foliar ( $\mathrm{Fa}$ ), pois tanto $\mathrm{Rw}$ quanto $\mathrm{Fa}$ apresentam tendência ao decréscimo com a ontogenia das plantas (Hunt \& Loomis, 1979). O decréscimo de Rw com a idade das plantas, em parte, é resultado do acúmulo gradativo de tecidos não-assimilatórios (Williams, 1946).

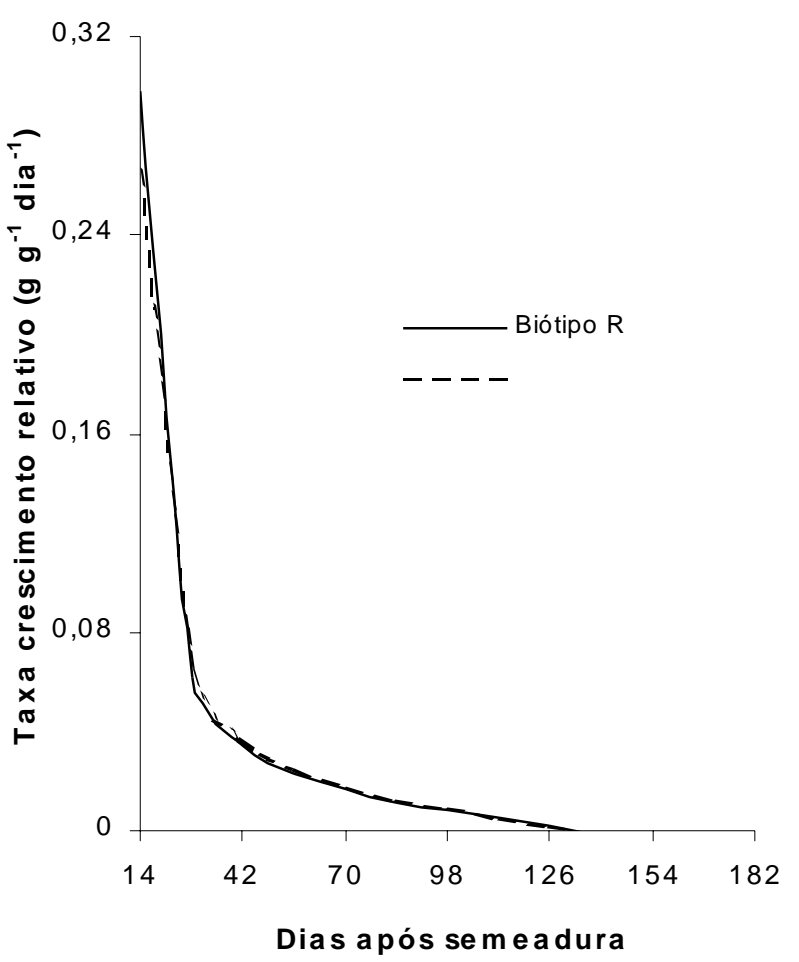

Figura 2 - Taxa de crescimento relativo de plantas de amendoim-bravo, em função do tempo. 
As curvas correspondentes à área foliar (Af) estão representadas na Figura 3. Os valores máximos obtidos foram de $1.513 \mathrm{~cm}^{2}$ planta $^{-1}$, aos 99 DAS (biótipo R), e $1.315 \mathrm{~cm}^{2}$ planta $^{-1}$, aos 98 DAS (biótipo S), decrescendo até o final das avaliações. Isso se deve ao fato de o amendoim-bravo ser uma planta de ciclo anual: inicialmente ocorre aumento na área foliar e, após atingir um valor máximo, começa a declinar, em função da senescência das folhas. Não houve diferença significativa entre os biótipos estudados em relação à área foliar (Tabela 2).

A taxa assimilatória líquida (Ea) é uma medida do aumento da matéria seca da planta por unidade de área foliar, evidenciando a eficiência do aparelho fotossintético. Essa característica varia mais com a idade da planta do que com os fatores climáticos (Watson, 1958). Os valores máximos de Ea obtidos foram de 0,00125 e 0,00106 $\mathrm{g} \mathrm{cm}^{-2} \mathrm{dia}^{-1}$ para os biótipos R e S, respectivamente (Figura 4).

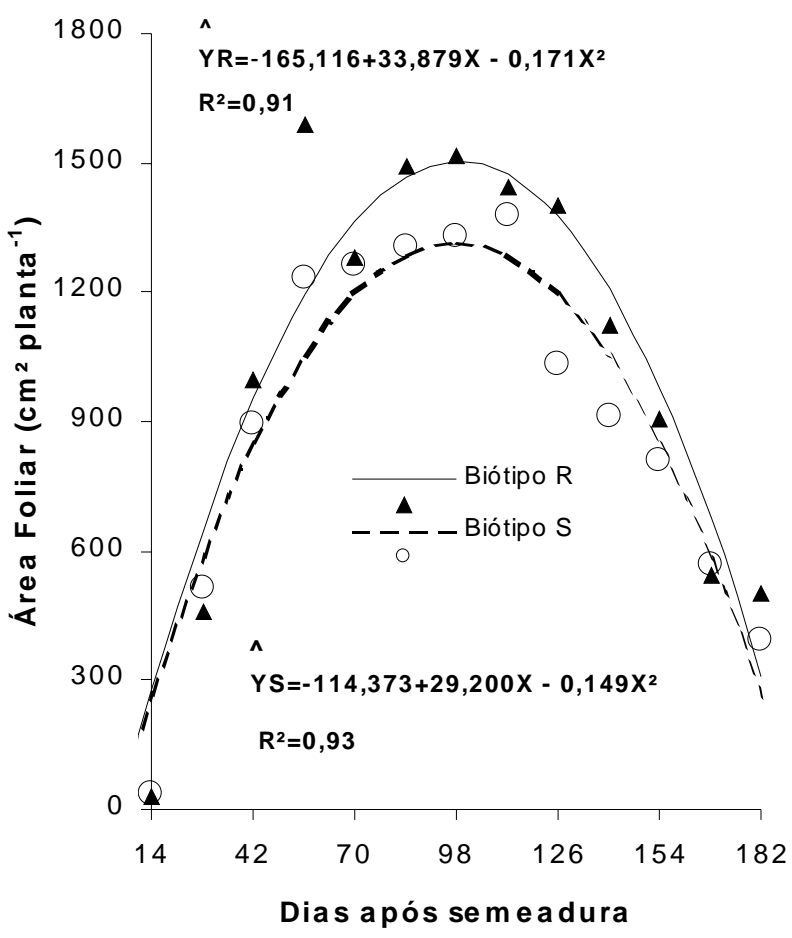

Figura 3 - Área foliar de plantas de amendoim-bravo, em função do tempo.

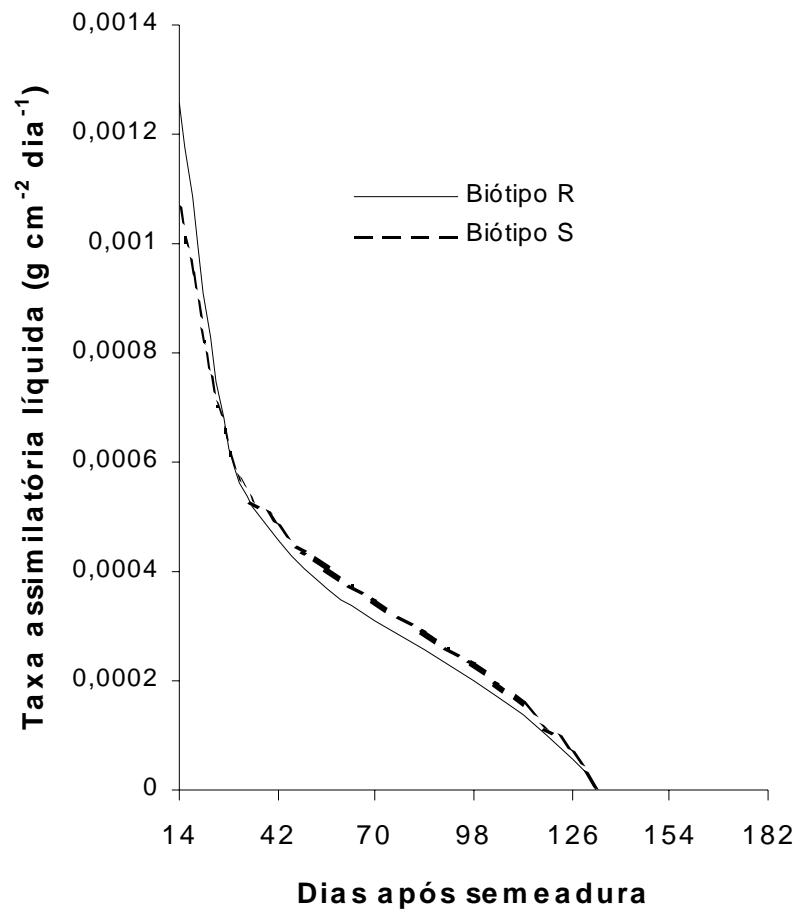

Figura 4 - Taxa assimilatória líquida de plantas de amendoim-bravo, em função do tempo.

A razão de área foliar $(\mathrm{Fa})$ permite detectar a translocação e a partição de assimilados para as folhas em relação à matéria seca da planta toda (Scott \& Batchelor, 1979). O comportamento dos dois biótipos em relação a Fa foi semelhante (Figura 5). Essa característica atingiu valores máximos de 237 e $249 \mathrm{~cm}^{2} \mathrm{~g}^{-1}$ para os biótipos $\mathrm{R}$ e $\mathrm{S}$, respectivamente. Isso ocorreu aos 14 DAS, havendo declínio a partir dessa data. A queda de Fa é ontogênica e indica que, progressivamente, a quantidade de assimilados destinada às folhas é diminuída (Scott \& Batchelor, 1979). Pode haver também abscisão de folhas, aparecimento de tecidos não-assimilatórios e, principalmente, raízes do amendoimbravo que competem decisivamente pelos assimilados produzidos, induzindo a senescência foliar. Fa pode decrescer também, em função do aumento da interferência de folhas superiores sobre as inferiores (auto-sombreamento), havendo diminuição da área foliar útil (Benincasa, 1988).

A razão de peso foliar $(\mathrm{Fw})$ é a relação entre a matéria seca foliar (Wf) e a matéria seca acumulada na planta toda (Wt). Fw expressa a

Planta Daninha, Viçosa-MG, v.19, n.1, p.51-59, 2001 
fração de matéria seca que não é exportada para o resto da planta. O valor máximo obtido pelo biótipo $\mathrm{R}$ foi de $0,42 \mathrm{~g} \mathrm{~g}^{-1}$, enquanto para o biótipo $\mathrm{S}$ foi de $0,55 \mathrm{~g} \mathrm{~g}^{-1}$ (Figura 6). Esses valores foram obtidos aos 14 DAS, sendo uma fase de grande crescimento foliar e estando os fotoassimilados alocados principalmente nas folhas. À medida que a planta envelhece, ocorre decréscimo em Fw (Melges et al., 1989).

Houve declínio na área foliar específica (Sa) com a idade das plantas de amendoim-bravo, sendo resultado da redução ou paralisação da expansão de Af, aliadas ao incremento em Wf. Geralmente, ocorre decréscimo de Sa durante a fase de crescimento vegetativo, pois as folhas não se expandem às mesmas taxas quando o crescimento progride (Scott \& Batchelor, 1979). A área foliar específica atingiu valores máximos de 564 e $446 \mathrm{~cm}^{2} \mathrm{~g}^{-1}$ aos 14 DAS para os biótipos R e S, respectivamente (Figura 7 ).

A matéria seca de raízes apresentou rápido incremento inicial, atingindo valores máximos de 6,3 g planta $^{-1}$, aos 107 DAS, e 6 g planta $^{-1}$, aos 113 DAS, para os biótipos R e S, respectivamente (Figura 8). Não houve diferença significativa entre os biótipos estudados em relação a essa característica (Tabela 2). Plantas de Kochia scoparia resistentes e suscetiveis aos herbicidas inibidores da ALS foram avaliadas, comparando-se o crescimento, a capacidade competitiva e a produção de sementes. Foi constatado não haver diferenças quanto ao crescimento e desenvolvimento dos biótipos estudados (Thompson et al., 1994; Christoffoleti et al., 1997).

Em relação ao caule, a matéria seca acumulada nesse órgão apresentou comportamento similar entre os dois biótipos estudados (Tabela 3). O maior valor obtido foi o mesmo para os dois biótipos (22 g planta $^{-1}$ ) (Figura 9). Características do crescimento de populações de caruru (Amaranthus retroflexus e A. powellii), suscetiveis e resistentes ao herbicida atrazine, foram avaliadas por Weaver et al. (1982), sendo verificado que plantas da população resistente de A. powellii apresentaram maiores biomassas de caule e altura de plantas do que as suscetiveis. Entretanto, as plantas resistentes e suscetiveis de $A$. retroflexus não diferiram significativamente em relação às características de crescimento estudadas.

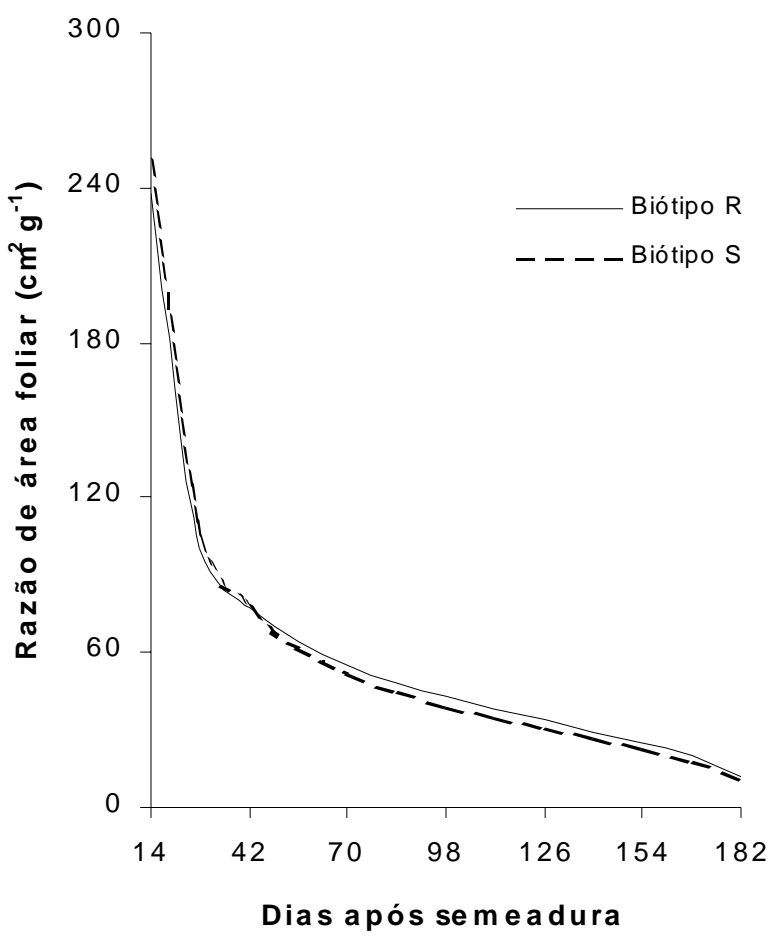

Figura 5 - Razão de área foliar de plantas de amendoim-bravo, em função do tempo.

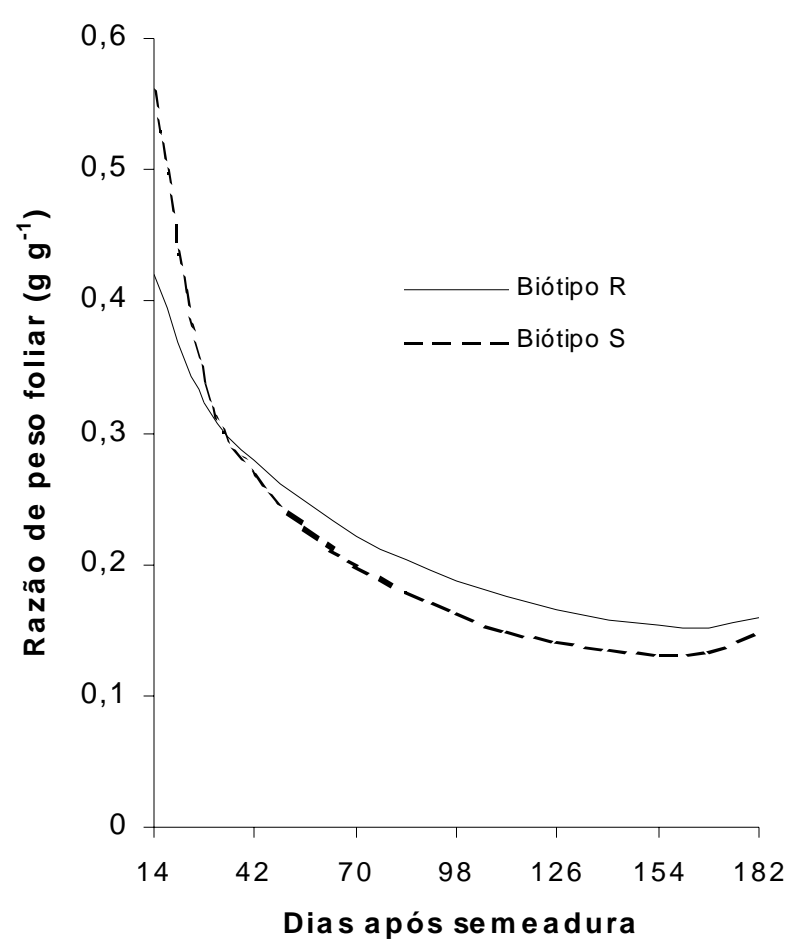

Figura 6 - Razão de peso foliar de plantas de amendoim-bravo, em função do tempo. 


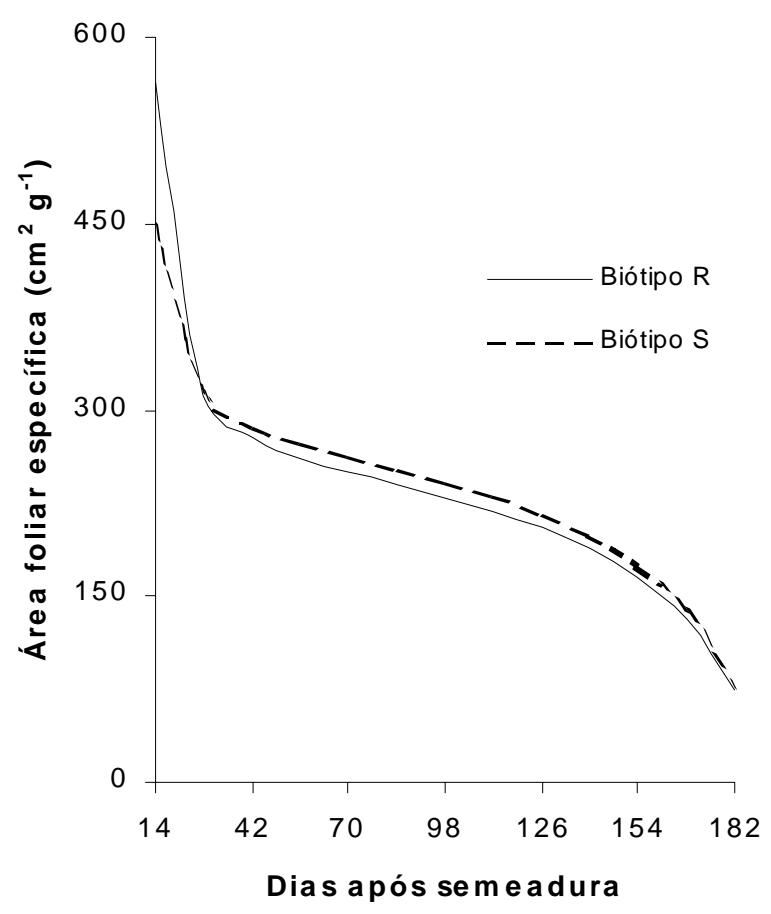

Figura 7 - Área foliar específica de plantas de amendoimbravo, em função do tempo.

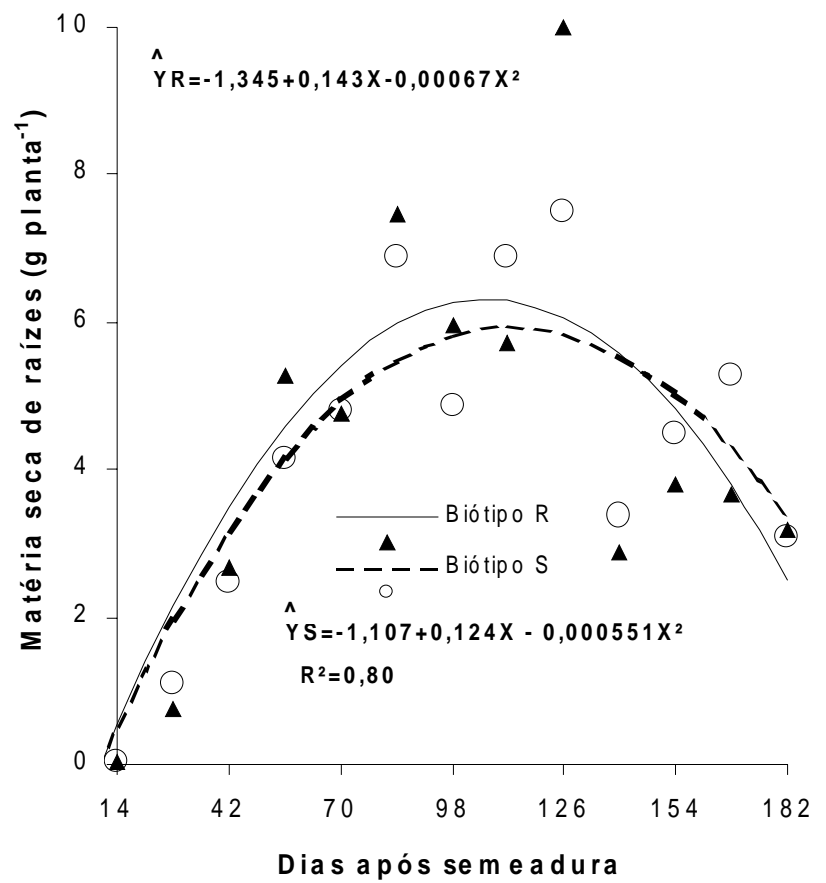

Figura 8 - Matéria seca de raízes de plantas de amendoimbravo, em função do tempo.

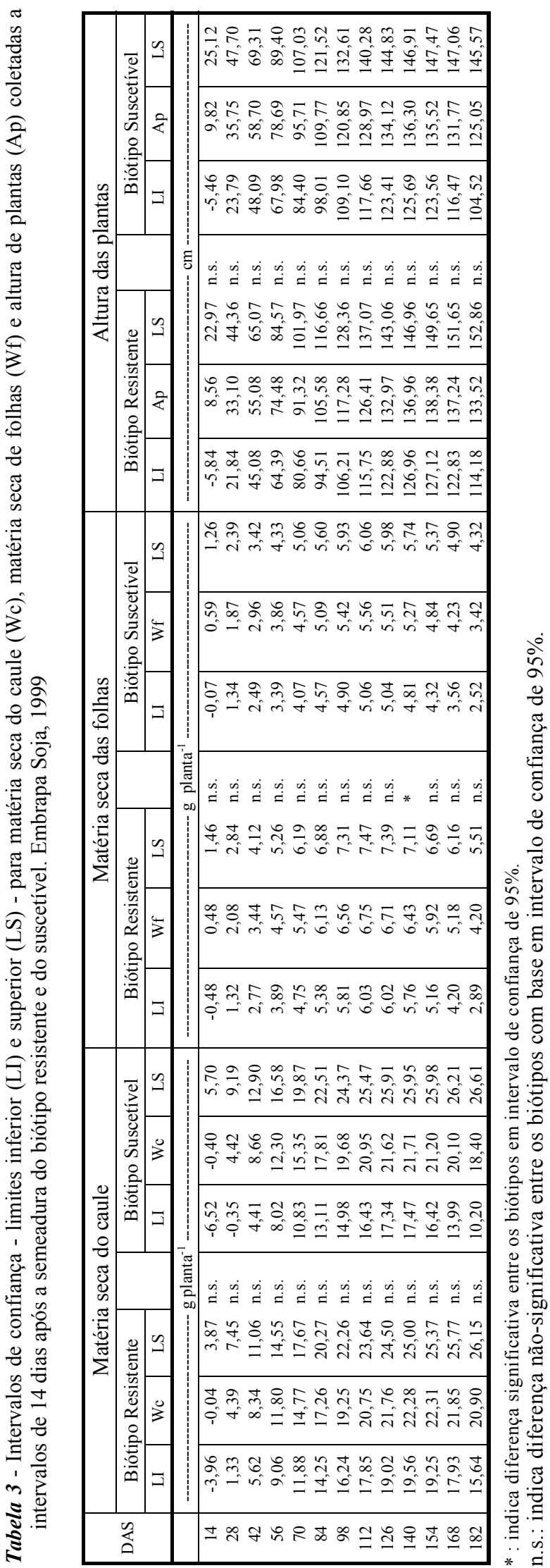




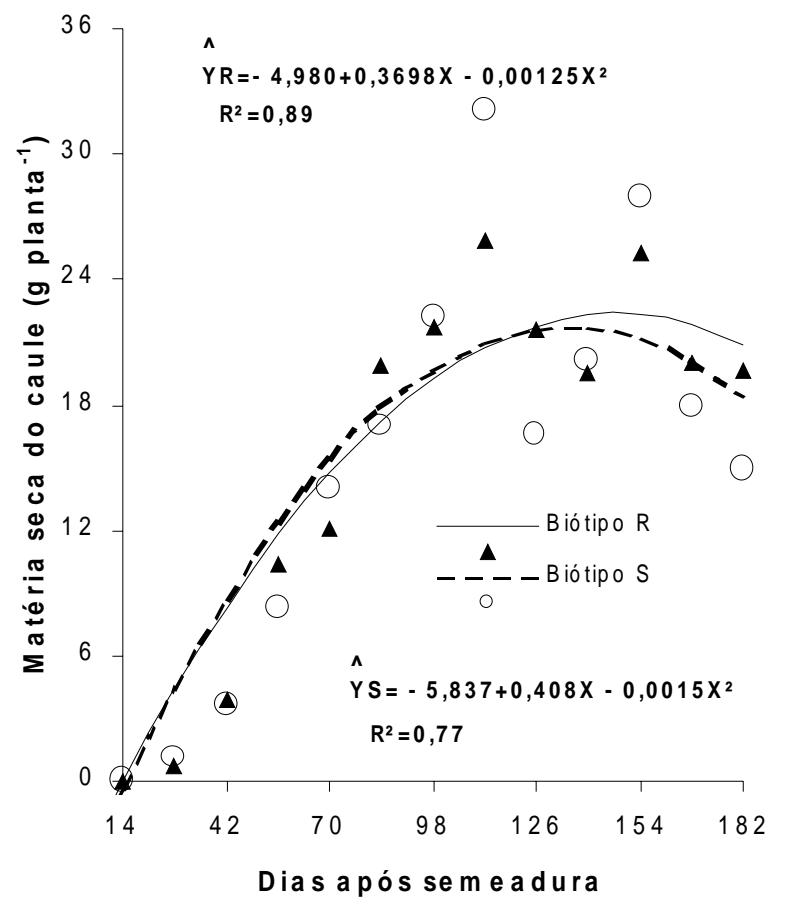

Figura 9 - Matéria seca do caule de plantas de amendoimbravo, em função do tempo.

A matéria seca acumulada nas folhas aumentou com a idade das plantas de amendoim-bravo e atingiu valores máximos de 6,8 $\mathrm{g}_{\text {planta-1 }}$, aos $118 \mathrm{DAS}$, e 5,5 $\mathrm{g} \mathrm{planta}^{-1}$, aos 116 DAS, para os biótipos R e S, respectivamente (Figura 10). Na avaliação realizada aos 140 DAS, foi verificada diferença significativa entre os biótipos quanto à matéria seca acumulada nas folhas, porém nas demais avaliações não houve diferença significativa (Tabela 3).

Os biótipos resistente e suscetível do amendoim-bravo apresentaram altura de plantas semelhante durante todo o ciclo vegetativo (Figura 11) (Tabela 3). Os valores máximos obtidos foram de $140 \mathrm{~cm}$, aos 156 DAS, e $138 \mathrm{~cm}$, aos 145 DAS, para os biótipos resistente e suscetivel, respectivamente.

Conclui-se, pois, que a matéria seca total acumulada pela planta e seus órgãos, bem como a área foliar e a altura, apresentam comportamentos semelhantes para ambos os biótipos, resistente e suscetivel. A taxa de crescimento relativo, a taxa assimilatória líquida, a razão de área foliar, a razão de peso foliar e a área foliar específica decrescem com a ontogenia das plantas de amendoim-bravo, sendo similares para ambos os biótipos. Os ciclos vegetativos dos dois biótipos estudados não apresentam diferenças significativas quanto ao crescimento e desenvolvimento.

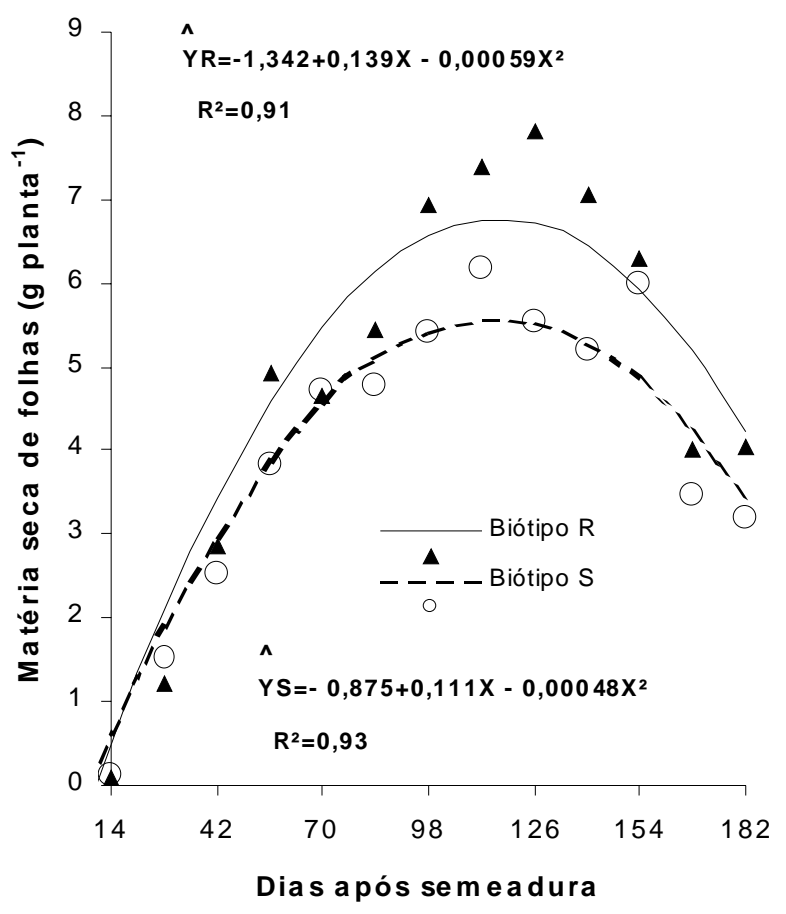

Figura 10 - Matéria seca de folhas de plantas de amendoimbravo, em função do tempo.

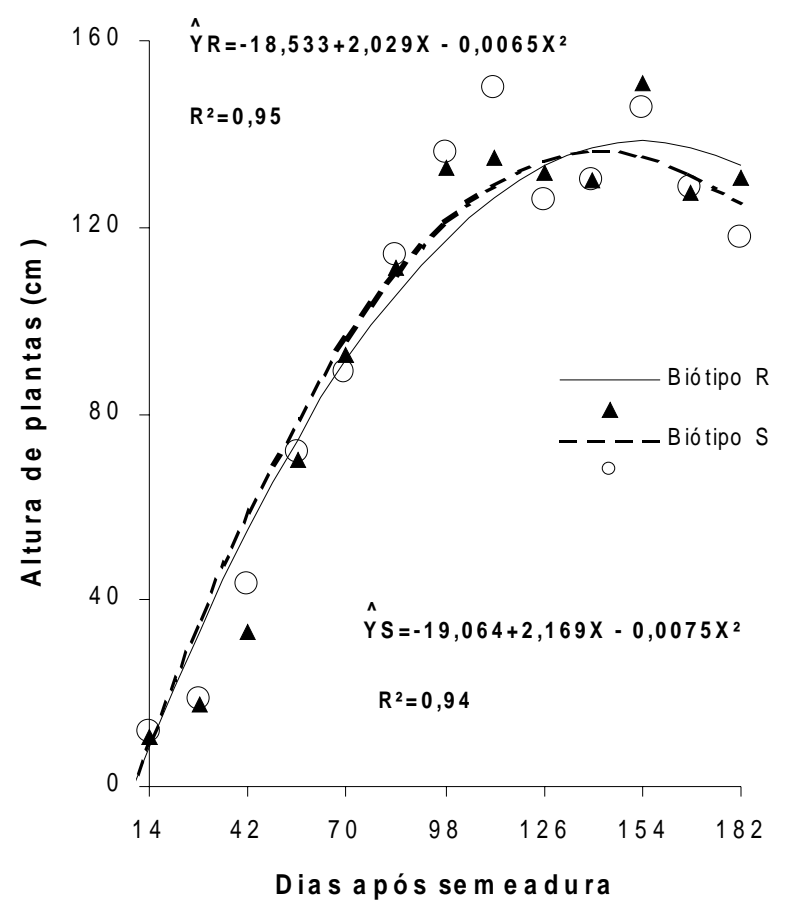

Figura 11 - Altura de plantas de amendoim-bravo, em função do tempo. 


\section{AGRADECIMENTOS}

Aos colegas José Erivaldo Pereira, pesquisador-estatístico da Embrapa Soja, Mário Nakano e Reinaldo Teruhico Moriyama, técnicos agrícolas da Embrapa Soja, pela colaboração. Aos auxiliares de operações da Embrapa Soja, Silvio Salvador, Alvino Custódio Vieira e José Olímpio Ribeiro da Mota.

\section{LITERATURA CITADA}

ALOCER-RUTHLING, M.; THILL, D.C., SHAFII, B. Differential competitiveness of sulfonylurea resistant and susceptible prickly lettuce (Lactuca serriola). Weed Technol., v.6, p.303309, 1992.

BENINCASA, M.M.P. Análise de crescimento de plantas (Noções básicas). Jaboticabal: FCAVUNESP, 1988. 41p.

BENINCASA, M.M.P.; RODRIGUES, T.J.D.; LEITE, I.C.; DAMASCENO, M.C.M.; BAZATTO, D.A. Estudos biológicos de Euphorbia tirucalli (avelós). Efeitos do tipo de solo e adubação sobre o índice de crescimento das plantas. R. Bras. Bot., v.3, p.49-53, 1980.

CAlBO, A.G.; SILVA, W.L.C.; TORRES, A.C. Comparação de modelos e estratégias para análise de crescimento. R. Bras. Fisiol. Veg., v.1., n.1, p.1-7, 1989.

CHRISTOFFOLETI, P.J.; WESTRA, P.; MOORE III, F. Growth analysis of sulfonylurea-resistant and-susceptible kochia (Kochia scoparia). Weed Sci., v.45, p.691-695, 1997.

CONARD, S.G.; RADOSEVICH, S.R. Ecological fitness of Senecio vulgaris and Amaranthus retroflexus biotypes susceptible or resistant to atrazine. J . Appl. Ecol., v.16, p.171-177, 1979.

GAZZIERO, D.L.P.; BRIGHENTI, A.M.; MACIEL, C.D.G.; CHRISTOFFOLETI, P.J.; ADEGAS, F.S.; VOLL, E. Resistência de amendoim-bravo aos herbicidas inibidores da enzima ALS. Planta Daninha, v.16, n.2, p.117-125, 1998.

HOLT, J.S.; RADOSEVICH, S.R. Differencial growth of two common groundsel (Senecio vulgaris) biotypes. Weed Sci., v.31, p.112-120, 1983.

HUNT, W.F.; LOOMIS, R.S. Respiration modeling and hypothesis testing with a dynamic model of sugar beet growth. Ann. Bot., v.44, p.517, 1979.

KISSMANN, K.G.; GROTH, D. Plantas infestantes e nocivas. São Paulo: BASF Brasileira, 1992. 798p. T. II.
MELGES, E.; LOPES, N.F.; OLIVA, M.A. Crescimento e conversão de energia solar em soja cultivada sob quatro níveis de radiação solar. Pesq. Agropec. Bras., v.24, n.9, p.1065-1072, 1989.

RADFORD, P.J. Growth analysis formulae: Their use and abuse. Crop Sci., v.7, n.3, p.171-175, 1967.

RICHARDS, F.J. The quantitative analysis of growth. In: STEWARD, F.C. (Ed.). Plant Physiology: A treatise. New York: Academic Press, 1969. p.3-76.

RODRIGUES, B.N.; ALMEIDA, F.S. Guia de herbicidas. 4.ed. Londrina: s.ed., 1998. 648p.

SCOTT, H.D.; BATCHELOR, J.T. Dry weight and leaf area production rates of irrigated determinate soybeans. Agron. J ., v.71, p.776-782, 1979.

THOMPSON, C.R.; THILL, D.C.; SHAFII, B. Growth and competitiveness of sulfonylurea-Resistant and-Susceptible Kochia (Kochia scoparia). Weed Sci., v.42, p.172-179, 1994.

VIDAL, R.A.; FLECK, N.G. Three weed species with confirmed resistance to herbicides in Brazil. In: MEETING OF THE WEED SCIENCE SOCIETY OF AMERICA, 1997, Orlando. Proceedings... Orlando: WSSA, 1997, v.37. p.100.

VIDAL, R.A., FLECK, N.G., THEISEN, G., NEVES, R., PETRY, L.A. Picão-preto e leiteira resistentes aos inibidores da ALS não apresentam resistência aos herbicidas com diferentes mecanismos de ação. In: CONGRESSO BRASILEIRO DA CIÊNCIA DAS PLANTAS DANINHAS, 21, 1997 Caxambu-MG. Resumos... Caxambu: 1997a. p.465.

VIDAL, R.A.; OLIVEIRA, N.A.; FLECK, N.G.; GUIMARÃES, F.B.; SILVA, N.G. Misturas de mecanismos de ação de herbicidas no controle de leiteira resistente aos inibidores da ALS. In: CONGRESSO BRASILEIRO DA CIÊNCIA DAS PLANTAS DANINHAS, 1997, Caxambu. Resumos... Caxambu: 1997b. p.468.

WATSON, D.J. The dependence of net assimilation rate on leaf area index. Ann. Bot., v.22, p.37$54,1958$.

WEAVER, S.E.; WARWICK, S.I.; THOMSON, B.K. Comparative growth and atrazine response of resistant and susceptible population of Amaranthus from Southern Ontario. J . Appl. Ecol., v.19, p.611-620, 1982.

WILLIAMS, R.F. The physiology of plant growth with special reference to the concept of net assimilation rate. Ann. Bot., v.10, p.41-72, 1946.

Planta Daninha, Viçosa-MG, v.19, n.1, p.51-59, 2001 